\title{
Medidas para el fomento y consolidación de un ecosistema favorable a la Economía Social en Galicia. La Red Eusumo
}

\author{
María Bastida \\ Ana Olveira Blanco \\ Teresa Savall Morera
}

RESUMEN: En Galicia se registra un incremento sostenido del número de entidades de economía social (ES) desde 2008, particularmente del número de cooperativas activas. Esta tendencia se mantiene incluso en años de mayor incidencia de la crisis económica. En este contexto, en 2012 nace la Red Eusumo para el fomento del cooperativismo y la ES, concebida con un doble objetivo: (a) ayudar y acompañar en la implantación de nuevos proyectos de ES (entendidos como aceleradores de empleo); y (b) contribuir a la consolidación de las empresas de ES existentes, mediante la mejora de su competitividad.

El objetivo de este trabajo es analizar el papel que la Red Eusumo, entendida como política pública de fomento de la ES, ha tenido desde su creación, tanto desde una perspectiva directa -en la creación de entidades de ES en Galicia, la promoción, difusión y mejora de conocimiento de la ES- como desde una indirecta, en lo que se refiere a su contribución al desarrollo de un ecosistema favorable al desarrollo y consolidación de la ES en la comunidad autónoma. Para ello, este trabajo se inicia con la descripción de la Red Eusumo, detallando sus objetivos, las bases de su funcionamiento, las entidades que la conforman y su financiación. A continuación, se ofrece una perspectiva genérica de la evolución de la ES gallega en el período 2008-2019, discriminando los períodos ante-post Eusumo para testar si existe un comportamiento diferencial. Posteriormente, se analiza la influencia que la Red Eusumo ha tenido en la configuración de un ecosistema favorable para la consolidación de la ES gallega. Para finalizar, se aportan las principales conclusiones del análisis, incluyendo unas sugerencias de mejora para el mejor alcance de objetivos y obtención de sinergias que favorezca el papel de esta herramienta como motor de desarrollo y consolidación de la ES en Galicia.

PALABRAS CLAVE: Economía social, políticas públicas, fomento de la economía social, ecosistema, Rede Eusumo, Galicia.

CLAVES ECONLIT: P43, J54, P16, P13.

Cómo citar este artículo / How to cite this article: BASTIDA, M., OLVEIRA-BLANCO, A. \& SAVALL-MORERA, T. (2020): "Medidas para el fomento y consolidación de un ecosistema favorable a la Economía Social en Galicia. La Red Eusumo", CIRIEC-España, Revista de Economía Pública, Social y Cooperativa, 98, 59-94. DOI: 107203/CIRIEC-E.98.15872.

Correspondencia: María Bastida, University of Santiago de Compostela, ORCID ID: https://orcid.org/00000002-3630-5629; Ana Olveira Blanco, University of Santiago de Compostela, ORCID ID: https://orcid.org/00000002-7165-3354, y Teresa Savall Morera, University of Valencia, ORCID ID: https://orcid.org/0000-0002-7464796. E-mail de contacto: maria.bastida@usc.es. 


\section{EXPANDED ABSTRACT}

\section{Measures to boost and consolidate an ecosystem favourable to Social Economy in Galicia. The Eusur mo Network}

In recent years, an ecosystem aimed at boosting Social Economy (SE) through the creation of different tools designed to tackle the different needs that the creation and consolidation of organisations within this sector require, has been consolidating in Galicia. The Eusumo Network, legally established by Decree 225/2012 of 27 November 2012, stands out among this group of measures.

The main objective of this paper is to analyse the role the Eusumo Network has played since its creation, as well as to consider its impact on the development and expansion of an ecosystem which favours the consolidation of SE in Galicia. In order to do this, this paper comprises two different parts: in the first one, our study is contextualised within the framework of the development of the public policies involved in the promotion of SE in Spain, and then the Eusumo Network is described. This description includes Eusumo's main objectives, the activities carried out to boost their achievement, the organisations that take part in the Network and the coordination process between them. This part ends with the analysis of the financial aid allocated to the Network and to the organisations that make it up, within the context of contemporary public policies that support SE.

The second part of the paper focuses on the results obtained by the Network in the last eight years, paying special attention to its impact on SE public policies in Galicia and, in particular, on the creation of an ecosystem favourable to the consolidation of $\mathrm{SE}$ in this region. Finally, the main conclusions and recommendations drawn from our study are summarised.

The study follows a descriptive and evaluative approach. To do this, a quantitative analysis of the data and indicators obtained from different sources has been carried out, namely: the activity reports of the different units responsible for SE in Galicia in the last years and the execution report of the Eusumo Network; the historical records of public procurement in Galicia; the statistical data provided by the official records of cooperatives and the budget allocation of the autonomous government before and after the creation of Eusumo.

The results of the study show, in the first place, that the Eusumo Network has fulfilled the aims set in the decree of its creation, which focused on contributing to the promotion and dissemination of

SE in Galicia, with particular attention to entrepreneurship and to the creation and consolidation of employment. 
In 2018 The Network included two hundred and six organisations, which show their commitment to cooperatives and SE. Besides, the Network has become highly influential, since its members include the most representative associations of SE; most city councils in Galicia; the three Galician universities; two of the four provincial councils, and all the Chambers of Commerce in the region. The number of participants in the dissemination activities of the Network has continued to grow since its creation. Furthermore, the percentages of new cooperatives (243\%) and of direct cooperative employment (158\%) stand out among these data. These results show an increasing effectiveness, in view of the most relevant direct results.

As for the improvement of the ecosystem, and therefore of its indirect results, the Network Eusumo has contributed to the passing of various legislation, measures and resources that support and favour Galician SE. The first one was Law 6/2016, of 4 May, of Social Economy in Galicia (LSEGA), which made Galicia the first region with specific legislation on this subject matter. Secondly, the Galician SE Strategy, passed in December 2018, with an allocation of 73 million euros. In addition, the Laboratories to Support the Creation of Employment of Organizations of Social Economy (POCTEC LACES) should be mentioned. This is a European programme intended to foster the creation and consolidation of SE organisations in the Euroregion (Galicia-North of Portugal). In 2019, Galicia was acknowledged as a European Social Economy Region (ESER 2019) by the European Commission. Finally, the analysis of the budgets that the Galician regional government (Xunta) invests in boosting SE, which have continued to increase since 2013, evinces an upward trend since the birth of the Eusumo Network. Specifically, they have increased from 11.49 euros million in 2013 to 20.10 in 2019, growing an average of $12.21 \%$ per year.

This study shows the direct and indirect contribution of public policies aimed at boosting SE, paying special attention to those labelled as advanced policies or hard model, which are characterised by their budgetary effort and by the diversity and innovation in the measures that they carry out. It also shows that long term public policies, such as the Eusumo Network, can contribute to improving and developing an ecosystem that boosts the area on which they are implemented. In the case of SE, it acts as a booster to set up other measures, affecting directly the improvement of budgetary policies in this issue.

In addition, this paper puts forward some suggestions for the functioning and future development of the Eusumo Network, contributing to its strengthening and helping to its continuation in time. Therefore, its contribution is twofold: (1) the Eusumo Network is identified as a public policy that favours the promotion of SE and (2) a group of six measures to improve its efficiency and efficacy, as well as, indirectly, the existing ecosystem, are presented.

KEYWORDS: Social economy, public politcies, promotion of the social economy, ecosystem, Eusumo Network, Galicia. 


\section{Introducción'}

El 27 noviembre de 2012 se publicaba en el Diario Oficial de Galicia el decreto 225/2012 de creación de la "Red Eusumo para el fomento del cooperativismo y la Economía Social". Este instrumento, según se extrae de la propia exposición de motivos, nace con dos objetivos fundamentales: (a) ayudar y acompañar a poner en marcha nuevos proyectos cooperativos en su calidad de motor de empleo; $y$ (b) contribuir a la consolidación de las empresas de economía social existentes, mediante la mejora de su competitividad.

Así definida, La Red Eusumo debe ser entendida como una herramienta pública de fomento y desarrollo de la Economía Social (ES) en Galicia, que se situaría a medio camino entre las políticas de apoyo tradicionales y las más recientes. Por un lado, su dotación es cofinanciada por los fondos procedentes del Fondo Social Europeo. Por otra, constituye una fórmula innovadora propuesta y diseñada en la comunidad autonómica gallega, sin equivalencia en el contexto de otras autonomías. En consecuencia, parece procedente analizar su efectividad. Este análisis permitirá, además, profundizar en el papel protagonista de la administración autonómica, tanto en los años más difíciles de la crisis económica -apostando por la creación y mantenimiento de la Red Eusumo (Olveira, 2016; Bastida, Cancelo y Olveira, 2019)- como más recientemente, reforzando su rol motor a través de la Ley 6/2016, de 4 de mayo, de la Economía Social de Galicia (LESGA).

El objetivo principal de este trabajo es analizar la labor realizada por esta entidad desde su constitución hasta la actualidad, así como estimar su impacto en el desarrollo e impulso un ecosistema favorable a la consolidación de la ES en Galicia. Para ello, el artículo se estructura en dos partes diferenciadas: en la primera, que sigue a esa introducción, se contextualiza el estudio en el marco de evolución de las políticas públicas que intervienen en el fomento de la ES en España, seguida de una descripción de la Red Eusumo. En ella se identifican sus objetivos principales, junto con las actividades implantadas para favorecer su consecución; las entidades participantes y el proceso de coordinación entre ellas. Esta fase termina con el análisis de la financiación destinada a la Red y a las entidades que la conforman, en el marco de las políticas públicas coetáneas de apoyo a la ES. La segunda parte del trabajo se centra en los resultados obtenidos por la Red en estos ocho años, destacando el estudio del impacto que ésta ha generado en las políticas públicas de fomento de la ES en Galicia y, en particular, en la configuración de un ecosistema favorable a la consolidación de la ES gallega. Para finalizar, se sintetizan las principales conclusiones y recomendaciones fundamentadas en el estudio precedente.

1.- La investigación a la que corresponde este artículo se encuentra dentro del proyecto ECOLILA financiado por la Consellería de Economía, Emprego e Industria en las subvenciones correspondientes a entidades colaboradoras de la Rede Eusumo para realizar actividades de promoción e impulso del cooperativismo y la economía social para los años 2019 y 2020. 
Los datos de este trabajo proceden de las diferentes memorias de actividades de las diferentes consejerías responsables de las competencias de cooperativismo ES en Galicia y de la propia Red Eusumo; el registro histórico de la plataforma de contratos de públicos de Galicia; los datos estadísticos de los diferentes registros de cooperativas -autonómico y provinciales- así como el análisis de los presupuestos de la comunidad autónoma gallega correspondientes a etapas pre y post Red Eusumo.

\section{El fomento de la economía social}

El análisis de las medidas de fomento de la ES en España debe comenzar por la referencia a la Constitución Española (CE), en el marco del Título VII Economía y Hacienda y más concretamente en al artículo 129 de esta norma. Mientras que en el primer punto del artículo se prevé la participación de la ciudadanía en todo tipo de organismos que afecten a la calidad de vida y el bienestar -incluyendo el sistema de Seguridad Social-, el segundo entra de lleno en el reconocimiento del derecho a la participación en la empresa, así como en el fomento de las cooperativas y el acceso a los medios de producción:

1. La ley establecerá las formas de participación de los interesados en la Seguridad Social y en la actividad de los organismos públicos cuya función afecte directamente a la calidad de la vida 0 al bienestar general.

2. Los poderes públicos promoverán eficazmente las diversas formas de participación en la empresa y fomentarán, mediante una legislación adecuada, las sociedades cooperativas. También establecerán los medios que faciliten el acceso de los trabajadores a la propiedad de los medios de producción.

En este segundo apartado subyacen tres mandatos -la participación de las personas trabajadoras en la empresa, el fomento del cooperativismo y el acceso a la propiedad de los medios de producción- cuya asunción conlleva la ordenación de la promoción y fomento de cooperativas y sociedades laborales. En consecuencia, las leyes que emanan de este precepto ponen en valor la fórmula cooperativa como medio para facilitar la integración de la ciudadanía en los diferentes sectores de actividad económica del país, y las sociedades laborales como medio de participación en los medios de producción.

La Ley 5/2011, de 29 de marzo, de economía social (en adelante, LES) viene a englobar lo dispuesto en el art. 129.1 y 129.2, al incluir en su ámbito de aplicación las cooperativas y sociedades laborales y potenciar la participación de los trabajadores en la empresa desde una dimensión finan- 
ciera. La LES nace con el objetivo de configurar un marco jurídico que favorezca la visibilidad de las entidades en el ámbito de ES, estableciendo sus principios orientadores; la necesidad de promocionarlas y estimularlas o la importancia de su rol como interlocutor con los poderes públicos, entre otras cuestiones. En este sentido, la mencionada ley coincide con lo dispuesto por el resto de las normas comparables europeas, aunque debe señalarse que alguna de ellas (concretamente, la francesa y la griega) hablan de economía social "y solidaria".

Seis años más tarde, en diciembre de 2017, se aprueba la Estrategia Española de Economía Social 2017-2020². Esta nueva herramienta de fomento de la ES nace con los objetivos de poner en valor y potenciar los elementos diferenciadores de las organizaciones de este ámbito en el marco de un mercado único, e impulsar dichas entidades con la puesta en marcha de programas, proyectos y fondos. En esta apuesta por el desarrollo e impulso ha influido la percepción de la capacidad de la ES para la generación de empleo de calidad, el aumento de bienestar público, el empoderamiento de la ciudadanía y el efecto sobre el desarrollo local, especialmente en contextos de crisis (Stiglitz, 2009; Amin, 2009; Navarro y Climent, 2010; Chaves y Demoustier, 2013; Wilkinson, 2014; Utting, 2015).

Para facilitar la consecución de estos objetivos, la Estrategia se divide en 11 ejes estratégicos de actuación que, a su vez, se articulan en 63 medidas. Tal y como se observa en la tabla 1, es posible distinguir como cada uno se orienta a la consecución de cada uno de los fines planteados. Así, los ejes estratégicos 8,9 y 10 (fomento de la visibilidad y difusión de la actividad de las entidades de la ES; de la igualdad de género y la inclusión social o de la responsabilidad social empresarial del sector, respectivamente) guardan relación con el objetivo de visibilizar los elementos diferenciales y los valores inherentes a la ES. Para la potenciación de las entidades del sector se diseñan dos ejes específicos (apoyo al empleo, el emprendimiento y la consolidación de empresas en este ámbito de la economía, 1 y 2). En la misma línea, otras iniciativas se vinculan con el refuerzo del ecosistema de ES, sea de forma instrumental (eje 3, eliminación de barreras jurídicas); institucional (fomento de la participación institucional del sector; desarrollo internacional o vinculación con la Agenda de los Objetivos de Desarrollo Sostenible ${ }^{3}$, ejes 6, 7 y 11) o buscando nuevos ámbitos de actuación para las entidades de ES (eje 4, generación de mecanismos innovadores de participación en sectores estratégicos, y 5 , impulso de la economía digital en actividades de ES).

2.- La primera Fase del Plan de Acción transcurre hasta 2019 y la segunda hasta 2020. Además, para garantizar la evaluación de los resultados se contempla la elaboración de un informe anual que debe presentarse ante el Consejo para el Fomento de la ES.

3.- Cabe destacar que la Resolución de la Asamblea General de las Naciones Unidas que aprueba la Agenda 2030 y especifica los 17 objetivos de desarrollo sostenible (ODS), destaca el papel de la ES como medio para facilitar la consecución de dichos objetivos. 


\section{Tabla 1. Ejes de actuación de la Estrategia Española de Eco- nomía Social 2017-2020}

Eje 1: Apoyo el empleo y al emprendimiento en el ámbito de la ES.

Eje 2: Impulso a la consolidación de empresas de ES y su crecimiento.

Eje 3: Análisis y desarrollo del marco jurídico de la ES, con el objeto de eliminar las barreras que puedan impedir o limitar su desarrollo.

Eje 4: Creación de mecanismos innovadores de participación de la ES en sectores estratégicos.

Eje 5: Impulso de la Economía Digital en las entidades de la ES.

Eje 6: Fomento de la participación institucional de la ES.

Eje 7: Desarrollo de la ES en el marco de la Agenda Internacional y, en especial, en Iberoamérica, Europa y Mediterráneo.

Eje 8: Incremento de la visibilidad de las entidades de la ES y difusión de su actividad.

Eje 9: Fomento de la igualdad de género y de la inclusión social en la ES.

Eje 10: Impulso de la responsabilidad social en el marco de las entidades de la ES.

Eje 11: Participación de la ES en el diseño e implantación de la Agenda de los Objetivos de Desarrollo Sostenible (ODS) de las Naciones Unidas.

FUENTE: Estrategia Española de Economía Social (2017-2020).

Una visión genérica de las medidas de fomento e instrumentos de apoyo a la ES permite situarlas a lo largo de un intervalo donde el protagonismo se desplaza desde el gobierno central hacia las administraciones autonómicas, aunque todas estas medidas se han caracterizado tradicionalmente por su insuficiencia e ineficacia (Chaves y Savall, 2013; Chaves, Savall, y Monzón, 2016). Las primeras medidas surgen en la década de los 80 , bajo las directrices y competencias de la Administración central (Chaves, 2011). En este contexto, se establecen líneas presupuestarias del programa Desarrollo de la Economía Social y del Fondo Social Europeo, transferidas anualmente a las comunidades autónomas, que son las que tienen la competencia para implantar las políticas. A su vez, los gobiernos autonómicos completan las cuantías con fondos obtenidos directamente de la Unión Europea y con fondos propios. El objetivo de estos fondos es el fomento de la inversión y el empleo en las cooperativas, sociedades laborales, y la ES en general. 
Posteriormente, y con carácter acumulativo en relación con las medidas presupuestarias, la Ley 20/1990 de 19 de diciembre sobre Régimen Fiscal de las Cooperativas establece una fiscalidad específica para estas entidades que les supone un claro ahorro fiscal. No obstante, cabe señalar que estas medidas son de aplicación exclusivamente en las cooperativas con beneficios, lo que limita su efectividad (Herrero, 2012). Por otra parte, sucesivas medidas similares dirigidas al fomento de emprendimiento, y en particular aquellas destinadas a las micro/pequeñas empresas, eliminan el carácter preferencial relativo del que gozaba la fiscalidad en las cooperativas (Chaves y Savall, 2013; Monzón, Ortega, Chaves, Fajardo, y Valdés, 2009).

También entre estas medidas emanadas del gobierno central se encuentra la posibilidad de capitalizar la prestación de desempleo para los perceptores que se incorporen como socios de cooperativas de trabajo y de sociedades laborales (R.D. 1044/1985). Esta medida ha probado ser efectiva en la creación de nuevas iniciativas empresariales, particularmente vía cooperativas de trabajo asociado, para personas que quieren reorientar su carrera profesional poniendo en marcha nuevos proyectos (Fernández, Martín y Lejarriaga, 2010; Lejarriaga y Martín, 2010).

Más recientemente, el fomento de la ES pasa a ser una competencia asumida por las diferentes Comunidades Autónomas, extendiendo su aplicación a más colectivos e innovando en el desarrollo e implantación de medidas más adaptadas a la realidad socioeconómica de cada territorio. No obstante, debe precisarse que las cooperativas y las sociedades laborales acaparan de forma mayoritaria el foco de atención en el marco de las entidades de ES de las políticas autonómicas. De hecho, mientras todas las comunidades autónomas (a excepción de Canarias) han ejercido su competencia autonómica a la hora de desarrollar una norma reguladora de las cooperativas, únicamente Galicia ha regulado la ES a nivel autonómico 4 .

En esta etapa descentralizada, Chaves (2010) constata la existencia de dos patrones en las políticas de fomento: un modelo de mínimos, con menor apoyo, y un modelo avanzado, caracterizado por un esfuerzo presupuestario mayor y por la diversidad e innovación en las medidas de apoyo. En este modelo más evolucionado destaca el fomento al cooperativismo en Andalucía, el País Vasco y Murcia (Chaves y Cardona, 2008; Chaves, Navarro y Arcas, 2011). La evaluación del impacto y efectos de estos programas debe realizarse a la luz de las drásticas reducciones en su dotación en el período de austeridad correspondiente inherente a la reciente crisis económica (Chaves y Savall, 2019; Chaves et al., 2016). Sin embargo, cabe destacar el esfuerzo realizado por las diferentes autonomías para diseñar instrumentos de fomento particularmente adaptados a la idiosincrasia de cada territorio, en un intento de desarrollar palancas de actividad específicamente orientadas a las heterogéneas realidades socioeconómicas. En el marco de desarrollo de estas políticas avanzadas, tres experiencias autonómicas ocupan un lugar destacado. Son programas de desarrollo en red, donde el impulso de

4.- El Parlamento de Canarias está en la actualidad debatiendo el Anteproyecto de Ley de cooperativas. Asimismo, debe destacarse que la comunidad aragonesa cuenta con un Anteproyecto de Ley de Economía Social de Aragón. 
la administración autonómica se combina con la consolidación de una red soporte de colaboración y coordinación entre diferentes organizaciones. Estos programas, diseñados e implantados en las tres autonomías históricas, están en activo en la actualidad y destacan por su carácter innovador y el grado de coordinación requerido para la implantación. En concreto, se trata de Koopfábrika (País Vasco), los Ateneos Cooperativos (Cataluña) y la Red Eusumo (Galicia) (Bastida, Olveira, y Cancelo, 2018).

\section{La Red Eusumo}

En mayo de 2011 se pone en marcha una entidad específicamente concebida para el impulso de la ES en Galicia, la Red Eusumo. Su creación formal, algo posterior, se sitúa al amparo del Decreto 225/2012, de 15 de noviembre por el que se crea y regula el funcionamiento de la Red Eusumo para el fomento del cooperativismo y la economía social (DOG del 27 de noviembre del mismo año). En la exposición de motivos se indica que la ES debe configurarse como un agente económico y social fundamental de la actividad económica gallega, en línea con lo establecido en la Unión Europea. Posteriormente, la Ley 6/2016, de 4 de mayo, de la economía social de Galicia (LESGA) refuerza el protagonismo de Eusumo como agente dinamizador en la promoción, fomento y difusión de la ES, de sus principios y valores. Así, el art. 15 de la LESGA (en el capítulo 4, destinado al fomento de la ES, establece que "las actividades de fomento y difusión de la economía social, de acuerdo con la orientación del Consejo de la Economía Social de Galicia, se impulsarán especialmente a través de la Red Eusumo para el fomento del cooperativismo y la economía social como instrumento creado por Decreto 225/2012, de 12 de noviembre".

El decreto de nacimiento de la Red destaca especialmente el papel del cooperativismo, por ser la figura societaria sobre la que Galicia tiene competencias plenas ${ }^{5}$ y también una de las figuras de la ES que cuenta con mayor tradición, lo que facilita su implantación. Estas características convierten al cooperativismo en una herramienta eficaz para alcanzar uno de los retos a los que pretende hacer frente la Red: el desempleo.

El proyecto nace con la vocación de aproximar el cooperativismo y la ES a la ciudadanía. Se indica la necesidad de dotar de medios y recursos a todo el territorio, de forma que todas las personas y entidades interesadas puedan tener acceso a ellos. Para ello, las diferentes entidades socias de la Red deben poner a disposición de ésta los espacios y recursos que tengan en su poder, con el fin

5.- Transferencia hecha por la Ley orgánica 16/1995, de 27 de diciembre, ampliando la recogida en el artículo 28.7 del Estatuto de autonomía de Galicia. 
de que puedan ser utilizados por aquellas organizaciones socias que las necesiten. Ello confiere la posibilidad de que la Red Eusumo pueda nacer con una amplia implantación y dotación de recursos, sin necesidad de tener que acometer un gran desembolso económico inicial.

\subsection{Objetivo}

El principal objetivo de la Red Eusumo es el fomento, difusión y divulgación del cooperativismo y de la ES, poniendo un especial interés en el emprendimiento y en la creación y consolidación del empleo. Para facilitar la consecución de este objetivo, se concretan diferentes ejes de actuación, reflejados en el articulado del decreto de creación ${ }^{6}$ :

a) Facilitar información, formación, orientación y asesoramiento en materia de cooperativismo y ES; difusión y fomento del autoempleo y el emprendimiento; asesoramiento y control de proyectos de economía social y cooperativas.

b) Proporcionar y facilitar medios para el emprendimiento, es decir, poner a disposición las instalaciones e infraestructuras para poder acoger el inicio de proyectos empresariales de ES. En la misma línea, aproximar los recursos de las entidades colaboradoras a potenciales interesados.

c) Aumentar el número de entidades y asociaciones en las diferentes redes de inter-cooperación existentes, tanto nacionales como internacionales, para la promoción de la ES y el cooperativismo.

d) Fomento, difusión, promoción y divulgación de las nuevas tecnologías de la información y la comunicación, I+D+i y trabajo en red.

e) Secundar la comercialización y la internacionalización, mediante cumbres internacionales y transfronterizas que fomenten la cooperación empresarial y el intercambio comercial.

f) Elaboración de estudios y análisis relacionados con temas de interés para la ES, así como para el desarrollo local.

g) Elaboración de materiales formativos y divulgativos sobre ES y cooperativismo.

h) Seguimiento de proyectos empresariales y de ES.

Como se puede observar, se establece un catálogo amplio de objetivos que permite dar cabida a cualquier actividad que pueda llevarse a cabo para el fomento y difusión del cooperativismo y la ES, destacando sobre todo aquellas que tienen que ver con el asesoramiento e información. En el art.4 del mencionado decreto se detallan estas actividades, que se pueden clasificar en tres grandes bloques vinculados con las tres grandes líneas de intervención de la Red (Tabla 2). El denominador común de todas estas actividades revela el objetivo subyacente a todo el funcionamiento de la Red Eusumo, el fomento del emprendimiento colectivo.

6.- Artículo 3 del decreto $225 / 2012$ del 15 de noviembre, por el que se crea la Red Eusumo para el fomento del cooperativismo y la economía social y se regula su funcionamiento. 


\section{Tabla 2 Actividades de la Red Eusumo}

\begin{tabular}{|l|l|}
\hline \multicolumn{1}{|c|}{ Ejes de Actuación } & \multicolumn{1}{c|}{ Actividades } \\
\hline $\begin{array}{l}\text { a) Información y sensibilización } \\
\text { sobre el valor de la ES, tanto en el } \\
\text { desarrollo de iniciativas emprende- } \\
\text { doras domo en el resultado de estas } \\
\text { entidades, más allá del puramente } \\
\text { económico }\end{array}$ & $\begin{array}{l}\text { Establecimiento de una línea permanente de investigación sobre posibilidades de } \\
\text { desarrollo local para el territorio. } \\
\text { Desarrollo de estudios sectoriales promoviendo la cooperación con entidades del } \\
\text { territorio. } \\
\text { Realización de campañas publicitarias de divulgación y difusión de las potencialida- } \\
\text { des, valores y realidades de la economía social. } \\
\text { Exploración y búsqueda de los yacimientos de emprendimiento de cara a identificar } \\
\text { los destinatarios de actuaciones formativas, informativas y de asesoramiento. }\end{array}$ \\
\hline $\begin{array}{l}\text { Asesoramiento e información en los centros. } \\
\text { Actividades de formación dirigidas a eventuales emprendedores. } \\
\text { beguimiento y tutorización de proyectos empresariales durante los primeros años. } \\
\text { doras, a través de servicios de } \\
\text { información especializada y aseso- } \\
\text { ramiento }\end{array}$ & $\begin{array}{l}\text { Apoyo al emprendimiento mediante la puesta a disposición de viveros para empre- } \\
\text { sas de ES. } \\
\text { Fomento de la coordinación de acciones y promoción de proyectos de carácter in- } \\
\text { ternacional. } \\
\text { Establecimiento de centros de documentación para su consulta por parte de entida- } \\
\text { des de economía social, personas emprendedoras y público en general. }\end{array}$ \\
\hline $\begin{array}{l}\text { c) Visibilizar la ES y el cooperati- } \\
\text { vismo entre los agentes sociales } \\
\text { y económicos, como vía para su } \\
\text { fomento y difusión. }\end{array}$ & $\begin{array}{l}\text { Promoción y dinamización del trabajo en red para la colaboración en temas comu- } \\
\text { nes, tales como la comercialización y la apertura conjunta de mercados. } \\
\text { Elaboración de acciones formativas en materia de nuevas tecnologías. }\end{array}$ \\
\hline
\end{tabular}

FUENTE: Decreto 225/2012 del 15 de noviembre, por el que se crea la Red Eusumo para el fomento del cooperativismo y la economía social y se regula su funcionamiento.

\subsection{Objetivo}

El gráfico 1 refleja la organización de la Red Eusumo, sintetizando su funcionamiento. La base del proceso está en la actividad en red, fundamentada en la colaboración. Las entidades socias comparten protagonismo, destacando el papel de liderazgo ostentando por el gobierno autonómico. 


\section{Gráfico 1. Entidades socias de la Red Eusumo}

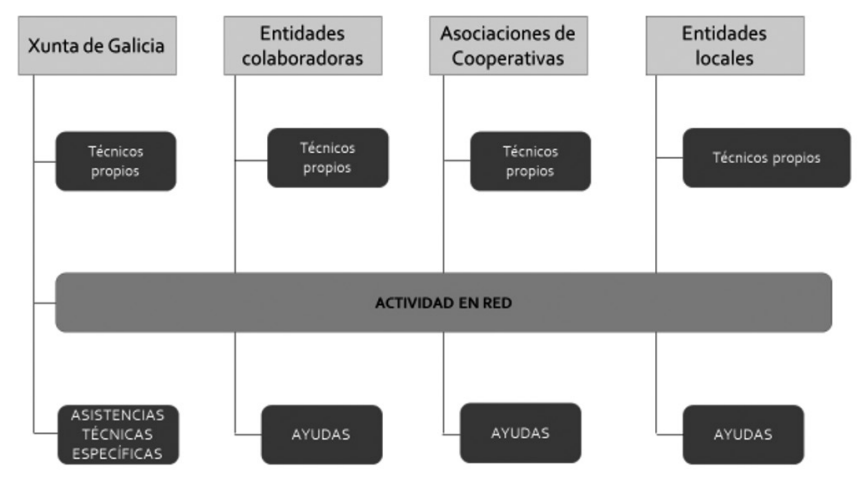

FUENTE: Memoria de actividades de la Red Eusumo (2014 y 2015). Actualizado a la estructura vigente en 2019.

Para la evolución, desarrollo, desempeño y difusión de las actividades referidas, la Red Eusumo se organiza en dos ejes: (1) actividades desarrolladas directamente por la Secretaría Xeral de Empre$\mathrm{go}^{7}$, concretamente a través de la Subdirección General de Economía Social, y que son realizadas, normalmente, por una asistencia técnica externa; y (2) las ejecutadas por las entidades socias. La Xunta de Galicia se reserva el papel de coordinación de la Red, aportando una serie de técnicos propios. Las tareas de asesoramiento y acompañamiento en el desarrollo y consolidación de nuevas entidades de ES son compartidas por todas las entidades ${ }^{8}$, realizadas en su caso a través de asesorías técnicas específicas. Las entidades ponen sus recursos -físicos o humanos- a disposición de la Red, para el desarrollo de las actividades que procedan. Periódicamente se convoca una orden de ayudas que, bajo el formato de subvención, se destinan a la financiación de las acciones al amparo de lo establecido en el marco de actuación de la Red. Concretamente, las actividades se cofinancian en una proporción del $80 \%$ (Xunta de Galicia) y $20 \%$ (entidades socias). En este sentido, cabe destacar que las líneas concretas objeto de subvención -y la correspondiente dotación- son determinadas por la administración autonómica, lo que refuerza su papel determinante en la conformación y refuerzo del sector de la ES gallega.

7.- El fomento de la ES en Galicia se centraliza en la subdirección general de Economía Social, dependiente de la Secretaría General de Empleo, a su vez enmarcada en la Consejería de Economía, Empleo e Industria.

8.- Entre las entidades colaboradoras destaca el papel de las asociaciones de cooperativas, que programan y ejecutan actividades de divulgación y formación cooperativa y son la principal referencia en la red de puntos de información y asesoramiento que se empieza a tejer. 
Si bien inicialmente había diferentes órdenes vinculadas con ámbitos de actividad diferenciales, en la actualidad se han unificado en una única convocatoria de subvención. Igualmente, la conformación específica de las actividades subvencionables se revisa y modifica en cada convocatoria. Esto permite inferir una de las grandes características de la Red Eusumo: se trata de un instrumento vivo y flexible, susceptible de adaptación a las diferentes realidades del entorno 0 al ámbito específico de actuación que se pretende priorizar en función de las políticas que se desee implantar.

Los objetivos fundamentales de la Red están fuertemente arraigados en todas sus actuaciones, y subyacen también en los requisitos y obligaciones que deben cumplir las entidades para ser socias de la Red (art.8 y 9). Así, éstas deben demostrar que sus actividades contribuyen al cooperativismo y la ES, y que revierten en el fomento del emprendimiento y del desarrollo local. Por otra parte, deben poner a disposición de la Red medios o recursos, como pueden ser los destinados a la realización de estudios y análisis de los distintos sectores productivos, al desarrollo de acciones formativas o de asesoramiento; 0 locales para albergar actividades de formación ${ }^{10}$. En definitiva, todos aquellos medios y recursos que tengan utilidad en el fomento del cooperativismo y la ES. Estos requisitos deben mantenerse durante el tiempo de permanencia de la entidad como socia de Eusumo.

Las entidades contribuyen directamente a las actividades de fomento y difusión de la ES participando en tareas de formación, asesoramiento e información enfocadas hacia el fomento del cooperativismo, el emprendimiento y la ES, sin menoscabo de las funciones y actividades que le sean propias. Relevante también es su papel en la visibilización de la ES y la propia Red. Así, deben identificarse con el distintivo de la Red Eusumo"1. Deben reflejar en todo documento o comunicación pública la colaboración con la Consellería de Economía, Empleo e Industria, el Fondo Social Europeo y la Red Eusumo, según proceda, y poner en conocimiento de la Dirección General competente toda aquella información que haya sido generada con motivo del cooperativismo y de la ES.

El desarrollo y crecimiento de la Red va ligado en gran medida a la asistencia técnica que se encarga de la coordinación y ejecución de asesoramientos y actividades por parte de la administración. A estos efectos, se convoca concurso público para la prestación de los servicios integrados en la Red Eusumo, consistente en la realización de actividades de dinamización, identificación de proyectos empresariales de economía social, formación dirigida a emprendedores interesados en impulsar pro-

9.- Pese al papel determinante de la Administración autonómica en la conformación de las líneas de ayuda, debe destacarse que las órdenes de subvención son sometidas al dictamen den COGACO - Consello Galego de Cooperativas-, donde tienen cabida las diferentes propuestas de las principales asociaciones de cooperativas (entre otras entidades).

10.- Estos locales se denominan Centros de la Red Eusumo, y tienen como finalidad la realización de las actividades de la Red, especialmente la información y sensibilización en materia de economía social; promoción e impulso del cooperativismo y el desarrollo local. Deben contar con un punto de información y asesoramiento (art. 6).

11.- En este sentido, conviene insistir en el esfuerzo realizado por consolidar una imagen corporativa que contribuya, indirectamente, a la visibilización de la propia Red y su importancia como agente central en la dinamización de la ES. Existe un manual de identidad corporativa (http:// www.eusumo.gal/imaxe-corporativa) en el que se determina un logotipo y distintivos que facilitan la identificación de las actividades y centros que la integran (art.7 y Anexo III). 
yectos dentro del sector de la ES. Para empresas ya constituidas, además de formación, se ofrece la elaboración y ejecución de un plan de asesoramiento y acompañamiento de proyectos empresariales. Además, debe ocuparse de la promoción de la Red, de su coordinación general y del seguimiento de las actividades desarrolladas en ella.

Estas actividades son cofinanciadas por el Fondo Social Europeo (FSE). En el período 2007-2013 se desarrollaron en el marco del Eje 4 del FSE Galicia. Actualmente se enmarcan en el Programa Operativo de Galicia FSE 2014-2020, como prioridad de inversión 8iii. En este marco, se destinan 5,4 millones de euros para el fomento de la ES, destacando la dotación al Programa Aprol de fomento de la contratación del sector, dotado en 2018 con algo más de 3 millones de euros. Esta iniciativa proporciona incentivos para la contratación de socios trabajadores en cooperativas y sociedades laborales, así como para el impulso de proyectos nuevos con especial atención a los dirigidos a menores de 30 años para fomentar el cooperativismo juvenil. Por tanto, el programa APROL es la principal línea de acción para el fomento de la creación de empleo en cooperativas y sociedades laborales, tanto desde la óptica de la propia entidad, como de la persona que accede a ese empleo.

La tabla 3 permite observar que la Red ha alternado un elevado número de contratos de gestión (siete) con períodos de ausencia de licitación, entre los que destacan el del año 2014 -en el que la Red Eusumo estuvo durante 5 meses sin asistencia técnica- y el comprendido entre 2016 y 2017, con un año entero sin contrato de gestión. Debe precisarse que esta circunstancia no implica que la Red quede sin actividad, sino que la administración gallega asume un papel protagonista en la coordinación de actividades. Es importante señalar que las actividades que dejan de realizarse son las de acompañamiento de grupos promotores, formación y difusión del cooperativismo y la ES que forman parte del propio contrato de licitación; al igual que la apertura correspondiente de los centros de referencia de la Red.

En la actualidad, está en ejecución el contrato resultante del proceso de licitación realizado en el año 2017 y que fue adjudicado por 309.000€. El contrato inicial contaba con una vigencia de dos años, que podrían ser prorrogados por otros dos. El período actual es, por tanto, el que cuenta con una mayor de estabilidad en cuanto a la asistencia técnica se refiere. 


\section{Tabla 3. Contratos de licitación y períodos de duración de la Red Eusumo}

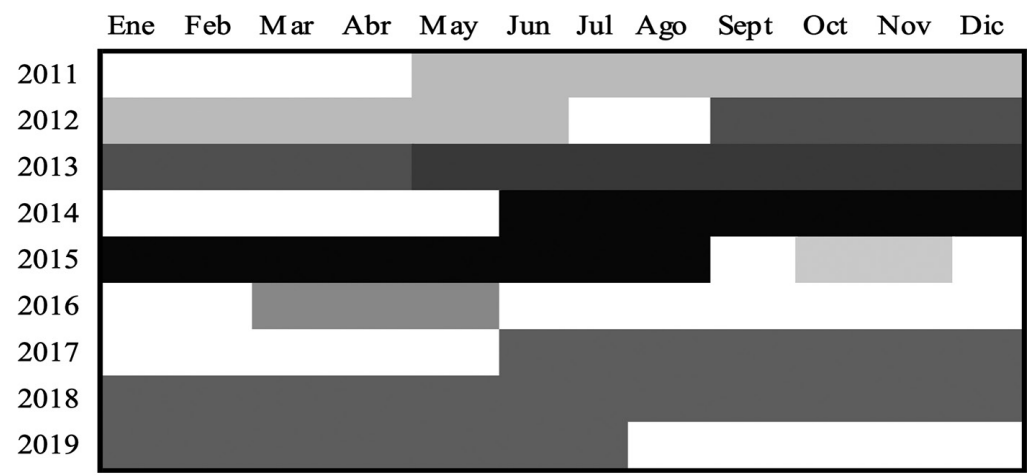

FUENTE: Elaboración propia con los datos incluidos en las memorias de actividades de la Red Eusumo, e histórico de contratación de la Xunta de Galicia.

\section{Evolución de la Red Eusumo: resultados}

Con un recorrido de más ocho años, la Red Eusumo cuenta con un bagaje suficiente para poder proceder a un análisis de su evolución con el fin de identificar sus resultados directos en este período (Bastida, Olveira y Cancelo, 2019). Para llevar a cabo esta tarea se analizaron los datos procedentes de las diferentes memorias de actividades de la propia Red (años 2014 a 2018), publicadas por la Secretaría Xeral de Emprego ${ }^{12}$; y los datos disponibles en los diferentes registros de cooperativas existentes en la comunidad -provinciales y autonómico- con el fin de profundizar en las características de las entidades creadas durante el citado período.

12.- La Red Eusumo actúa bajo la dependencia de la Secretaría General de Empleo de la Xunta de Galicia, competente en materia de cooperativas y economía social en esta comunidad autónoma (Decreto 175/2015, del 3 de diciembre, que establece la estructura orgánica de la Consellería de Economía, Emprego e Industria. La Secretaría General tiene competencia exclusiva en materia de planificación, promoción y coordinación de actividades de la Red. 


\subsection{Entidades adheridas}

En la actualidad, la Red Eusumo cuenta con 206 entidades socias entre las que se encuentran asociaciones de ES, entidades locales y supramunicipales, grupos de desarrollo rural y costero, las tres universidades gallegas, asociaciones y fundaciones, asociaciones empresariales, cámaras de comercio y algunas cooperativas (sobre todo las ligadas al asesoramiento empresarial).

Como se puede comprobar en el gráfico 2, desde 2013 se ha duplicado el número de entidades asociadas a la Red, que ha aumentado a un ritmo promedio superior al $15 \%$ anual ${ }^{13}$. En este incremento tienen un papel fundamental los ayuntamientos adheridos, sea como entidades independientes 0 como miembros de entidades supramunicipales (diputaciones, mancomunidades o consorcios). En conjunto, aportan un $70 \%$ de los socios totales de la Red, lo que los convierte en la principal fuente de entidades asociadas. Asimismo, cabe señalar la reciente adhesión de la Universidade Católica Portuguesa, entidad ajena al ámbito territorial gallego, en el contexto de conformación de la Euro región Galicia-Norte de Portugal.

\section{Gráfico 2 Entidades socias de la Red Eusumo}



FUENTE: Elaboración propia a partir de los datos incluidos en las memorias de actividades de la Red Eusumo. 
En la desagregación de los datos correspondientes al "resto" de las entidades, cabe destacar que se encuentran incluidas todas las uniones de cooperativas, las agrupaciones de entidades representativas más importantes de las otras familias de ES (centros especiales de empleo sin ánimo de lucro, empresas de inserción y sociedades laborales); las tres universidades gallegas, la totalidad de las cámaras de comercio y dos de las cuatro diputaciones provinciales gallegas.

Se puede decir, por tanto, que la red Eusumo ha conseguido englobar a la mayor parte de las entidades que participan en la promoción, defensa y estudio de la ES en Galicia.

\subsection{Actividades de difusión de la ES}

La línea de actuación donde la Red realiza un mayor número de actividades es la de difusión y formación en materia de $\mathrm{ES}^{14}$. Según se desprende de las memorias de ejecución correspondientes al período 2014-2018, en ese periodo se realizaron casi mil acciones de este tipo, con un alcance directo de casi 20.000 personas.

Según se observa en la tabla 4, el número de actividades se mantiene más o menos constante con independencia de la situación de la asistencia técnica de la Red, lo que parece indicar que la ejecución de este tipo de acciones (principalmente bajo el formato de jornadas) recae con un mayor peso en las entidades socias que en la propia administración autonómica. No ocurre lo mismo si se atiende al número medio de personas asistentes por actividad. Aunque las variaciones no son muy elevadas -el rango se mueve entre 16 y 24 personas- la tendencia se sitúa al alza. En el período analizado, el número total de asistentes se ha incrementado un $36,8 \%$.

\section{Tabla 4. Actividades de formación y divulgación realizadas por la Red Eusumo (2014-2018)}

\begin{tabular}{|c|c|c|c|c|c|c|}
\hline \multicolumn{6}{|c|}{ Actividades de divulgación y Formación } & \multirow[b]{2}{*}{ Total } \\
\hline & 2014 & 2015 & 2016 & 2017 & 2018 & \\
\hline Número de Actividades & 171 & 201 & 191 & 203 & 199 & 965 \\
\hline Número de asistentes a jornadas & 3.450 & 3.241 & 4.209 & 4.276 & 4.721 & 19.897 \\
\hline Media de asistentes & 20 & 16 & 22 & 21 & 24 & 21 \\
\hline
\end{tabular}

FUENTE: Elaboración propia a partir de los datos incluidos en las memorias de actividades de la Red Eusumo.

14.- La heterogeneidad en los datos incluidos en las memorias de actividades de los sucesivos años de funcionamiento de la Red Eusumo impiden desagregar las actividades de formación y de divulgación. No obstante, este dato sí se refleja en las memorias de resultados de 2017 y 2018. En ambos casos, las actividades de divulgación suponen más del $60 \%$ del total de las actividades recogidas en este epígrafe. 
Hasta la última de las memorias publicadas (correspondiente al ejercicio 2018), no se facilitan datos desagregados sobre el perfil de personas asistentes a las jornadas formativas. En este año, las mujeres presentan una mayor participación tanto en las actividades formativas -aquellas que tienen como objetivo la mejora de las capacidades técnicas del personal de las entidades del sector para favorecer su competitividad- como en las divulgativas -las que tienen como fin dar a conocer la ES y sus valores como alternativa de emprendimiento-. Así, en el primer caso las mujeres suponen el 59,3 $\%$ del total de asistentes, frente al $40,7 \%$ de presencia masculina. La participación es algo más equilibrada en las actividades de divulgación (54,3 \% y 45,7\% para mujeres y hombres, respectivamente).

Por otra parte, en lo que se refiere a la difusión y visualización de la ES, se ha realizado un esfuerzo importante de presencia en redes sociales. Así, la Red Eusumo cuenta con redes sociales propias -Facebook, Twitter y Youtube- que, según los datos de la memoria de actividades de 2018, cuentan con un total de 10.385 seguidores $^{15}$, 4.359 publicaciones y 1,6 millones de impresiones y visualizaciones. Estos datos son de particular relevancia, en tanto a su potencial acceso a personas de menor edad que pueden encontrar en la ES una vía de emprendimiento y desarrollo profesional, y sitúan a la Red como un canal de comunicación preferente de la ES en Galicia.

\subsection{Nuevas entidades de ES}

Aunque la Red nace con vocación de promover y difundir al conjunto de entidades de la ES, se hace particular incidencia en el fomento del emprendimiento en particular bajo la fórmula cooperativa. A este respecto, pese a algún trabajo crítico (Jaén, 2017) por lo general se reconoce la capacidad de la ES y cooperativa para reaccionar a los efectos de la crisis económica en el empleo y el ajuste de salarios, y para generar empleo de calidad (Chaves y Monzón, 2018; Chaves y Savall, 2019; Díaz y Marcuello, 2014; Lejarriaga, Bel y Martín, 2013; Martínez-Carrasco, López y Marín, 20136). Mientras que las sociedades capitalistas reducen plantilla para obtener beneficios, las cooperativas priorizan el mantenimiento de puestos de trabajo aun a costa de la reducción de anticipos laborales (equivalente a salarios). En consecuencia, el emprendimiento colectivo se ha revelado como una alternativa válida para salir del desempleo y reinsertarse en el mercado laboral (Lejarriaga, Bel y Martín, 2013). Además, estas entidades han demostrado tener una mayor flexibilidad y capacidad de adaptación ante circunstancias adversas que otras fórmulas jurídicas; $y$ también ser capaces de facilitar una vía

15.- Esta cifra supone duplicar el número de seguidores de la Red desde 2015, aunque no se puede obviar el efecto reciente de la evolución de estas nuevas vías de comunicación en el entorno general.

16. - El carácter contra cíclico del empleo en las sociedades cooperativas ha sido ampliamente estudiado en las últimas décadas. Después de las primeras referencias (Monzón, 1991), recientemente las investigaciones se han centrado en el análisis de los efectos de la crisis económica-financiera de 2008, concluyendo que las entidades de ES tienen una mayor capacidad de adaptación al entorno y, en consecuencia, son más resistentes en términos de empleo (Calderón y Calderón, 2012; Díaz y Marcuello, 2010; Navarro y Climent, 2010; Sala, Torres y Farré, 2015; Salinas y Osorio, 2012. No obstante, cabe destacar que el reciente trabajo de Sala, Torres y Farré (2018) encuentra que la reciente crisis económica revirtió en parte este comportamiento contracíclico. 
de acceso al empleo para grupos desfavorecidos y para personas excluidas socialmente (Melgarejo, Arcelus y Simón, 2007; Monzón y Chaves, 2012; Monzón, 2010).

En concordancia con este impulso al emprendimiento, la Red realiza actividades de asesoramiento y acompañamiento a personas que desean constituir su empresa bajo fórmulas de ES. Así durante el período 2014-2018 (tabla 5), se acompañaron un total de 583 grupos promotores, lo que supone casi 1.700 personas asesoradas.

\section{Tabla 5. Resultados de la Red Eusumo en la creación de entidades de ES (2014-2018)}

\begin{tabular}{|l|r|r|r|r|r|r|}
\hline & 2014 & 2015 & 2016 & 2017 & 2018 & Total \\
\hline Grupos promotores & 134 & 149 & 109 & 79 & 112 & 583 \\
\hline Asesoramiento personas socias & 471 & 518 & 237 & 145 & 322 & 1.693 \\
\hline Entidades cooperativas constituidas & 21 & 39 & - & 40 & 72 & $\mathbf{2 2 3}$ \\
\hline Puestos de trabajo cooperativos directos & 95 & 149 & - & 171 & 245 & 660 \\
\hline Sociedades Laborales constituidas & 42 & 35 & 29 & 29 & 45 & 180 \\
\hline
\end{tabular}

FUENTE: Elaboración propia a partir de los datos obtenidos en las memorias de las actividades. Los datos correspondientes a 2016 no figuran en la memoria del ejercicio.

En cuanto a las entidades constituidas, se constata un aumento sostenido en el tiempo en particular del número de cooperativas, y un comportamiento algo más irregular de las sociedades laborales. Estos datos, puestos en relación con la evolución en la constitución de cooperativas en Galicia desde el 2008 hasta el 2018 (gráfico 3) permiten determinar la posible influencia de la Red en el nacimiento de este tipo de entidades en Galicia. 


\section{Gráfico 3. Cooperativas constituídas en Galicia 2008-2018}



FUENTE: Elaboración propia a partir de los datos de los registros de cooperativas.

En este contexto, se observan diferentes ciclos: uno ascendente, hasta 2008; una caída en el ritmo de creación de cooperativas desde ese año hasta 2011; un tercer ciclo de incremento que se frena bruscamente en 2015 y un último periodo expansivo que comienza en 2018. El primer retroceso (2008-2010) se produce con la irrupción de la crisis económica, que se ve compensada con el propio nacimiento de la Red en el 2011. El segundo período de retroceso (2016-2017) coincide con el mayor periodo de carencia en la asistencia técnica de la Red, que permaneció sin licitación desde mayo de 2016 a junio de 2017. Cabe recordar que, además de apoyar la coordinación y la realización de actividades, la Red se encarga directamente del asesoramiento de grupos promotores con sedes de referencia en las cuatro provincias. Por otra parte, se observa que en el período previo al nacimiento de la Red Eusumo (2008-2012) se inscribieron en promedio anual 48 nuevas cooperativas, mientras que a partir de ese momento (2013-2018) la media pasó a ser superior a 60 cooperativas nuevas anuales.

El notable incremento registrado en el reciente 2018 merece un comentario aparte. En este caso, confluyen dos circunstancias que parecen afectar positivamente la constitución de sociedades: por un lado, la estabilidad en la asistencia técnica de la Red; por otro, la introducción en el ordenamiento jurídico gallego de las cooperativas juveniles ${ }^{17}$ (LESGA) y de las microcooperativas ${ }^{18}$ (ley 5/2017, de 19 octubre, de fomento de la implantación de iniciativas empresariales en Galicia). Aunque sería pre-

17.- Se trata de cooperativas constituidas mayoritariamente por jóvenes comprendidos entre dieciséis y veintinueve años (treinta y cinco años en el caso de personas con capacidades diferentes) que pongan en común su trabajo personal.

18. - Este cambio normativo permite que el número mínimo de personas socias necesarias para poner en marcha un proyecto cooperativo sea de dos (anteriormente eran tres). 
cipitado establecer una relación causa-efecto entre estas disposiciones y la creación de cooperativas por lo reciente de su implantación (2017 y 2016, respectivamente), sí se puede destacar que entre 2016 y 2018 inician su actividad 15 cooperativas juveniles, y que en 2018 se registran por primera vez 33 cooperativas con dos socios fundadores. Es decir, que el $46 \%$ de las nuevas cooperativas inscritas en 2018 son microcooperativas. Sin embargo, únicamente el 9,2\% son cooperativas juveniles.

A modo de conclusión, la tabla 6 resume los principales resultados previamente analizados, según se recoge en los Balances de Actividad elaborados por la Xunta de Galicia.

\section{Tabla 6. Balance Resultados de la Red Eusumo 2014-2018}

\begin{tabular}{|l|r|r|r|r|r|r|r|}
\hline & & & & & & \multicolumn{2}{|c|}{$2014-2018$} \\
\hline & 2014 & 2015 & 2016 & 2017 & 2018 & \multicolumn{1}{c|}{ Total } & $\%$ \\
\hline$N^{0}$ Personas Socias & 133 & 153 & 168 & 203 & 206 & 863 & $54,89 \%$ \\
\hline Actividades de Divulgación y formación & 171 & 201 & 191 & 203 & 199 & 965 & $16,37 \%$ \\
\hline Asistentes a jornadas divulgación formación & 3.450 & 3.241 & 4.209 & 4.276 & 4.721 & 19.897 & $36,84 \%$ \\
\hline Tareas de asesoramiento & 134 & 149 & 109 & 79 & 112 & 583 & $-16,42 \%$ \\
\hline Personas/socios en asesoramiento & 471 & 518 & 237 & 145 & 322 & 1.693 & $-31,64 \%$ \\
\hline Entidades coops constituidas & 21 & 39 & - & 40 & 72 & 172 & $242,86 \%$ \\
\hline Puestos de trabajo cooperativos directos & 95 & 149 & - & 171 & 245 & 660 & $157,89 \%$ \\
\hline
\end{tabular}

FUENTE: Elaboración propia a partir de los datos de las memorias de la Red Eusumo.

El indicador más positivo es el que refleja el número de socios adheridos a la Red. En el resto de los indicadores -relacionados con las actividades concretas-, se detecta mayor variabilidad e incluso un ligero retroceso en el bienio 2016-2017. La ausencia de licitación para la gestión de actividades de la Red, vinculada con esos ejercicios, está probablemente relacionada con ese descenso. No obstante, la valoración de datos acumulados desde el inicio del funcionamiento de la Red permite una evaluación global positiva desde su implantación. 


\section{Mejora del ecosistema de la economía social en Galicia}

La Red Eusumo desde su creación ha producido unos resultados directos en términos de empresas creadas, cursos de formación y difusión importantes, como se ha reflejado en los epígrafes precedentes. Pero, además, la Red también ha sido un elemento clave para la aparición de nuevas políticas de fomento, dado que ha conseguido aunar intereses de las distintas familias de la economía social, y llevar sus reivindicaciones a la esfera política. Estas nuevas medidas se pueden considerar resultados indirectos generados por la Red.

\subsection{Ley gallega de economía social}

En primer lugar, cabe hacer referencia a la Ley 6/2016, de 4 de mayo, de Economía Social de Galicia $^{19}$ (LESGA). Esta ley dota a Galicia de un marco normativo propio en materia de ES que se adapta a la realidad socioeconómica de la comunidad autónoma. Este texto legal, al igual que en el caso de la normativa española, conceptualiza la ES como el conjunto de actividades económicas y empresariales que, en el ámbito privado, llevan a cabo aquellas entidades que se rigen por los valores y principios recogidos en la citada ley, y que persiguen el interés colectivo de las personas que las integran, o el interés general económico o social (art.3). Estas entidades comparten desafíos propios de la sociedad moderna como la conciliación de la vida familiar, personal y laboral; la apuesta por la innovación, la implicación social en el entorno o la defensa del desarrollo sostenible.

La LESGA identifica en el capítulo II las entidades incluidas en el ámbito de aplicación de la ley: cooperativas, sociedades laborales, empresas de inserción, centros especiales de empleo, las cofradías de pescadores, sociedades agrarias de transformación, mutualidades, asociaciones o fundaciones que lleven a cabo actividad económica y entidades singulares. Dado que la ley gallega pretende adaptar el marco regulatorio estatal a la realidad socioeconómica de Galicia, incluye de forma expresa a las comunidades de montes vecinales en mano común, institución peculiar recogida en el derecho civil gallego.

Además, regula el marco de participación pública del sector para favorecer la coordinación de actuaciones en materia de ES. Así, el capítulo III de la Ley incluye la creación del Consejo de la Economía Social de Galicia como órgano consultivo y asesor para las actividades relacionadas con 
la ES, especialmente en el ámbito de su promoción y difusión. La ley se expande, en el capítulo IV en la determinación de actividades para la promoción, fomento y difusión de la economía social en la comunidad gallega. En este contexto, como se ha referido anteriormente, se potencia el papel de la Red Eusumo como herramienta prioritaria en el fomento del cooperativismo y la economía social.

Como elemento diferencial de la LESGA, cabe destacar que otorga un papel protagonista a la capacidad de la ES como generadora de empleo. En este contexto, la LESGA incide especialmente en este aspecto, introduciendo a través de la Disposición Adicional primera una modificación de la Ley 5/1998, de 18 de diciembre, de cooperativas de Galicia, para incidir en la promoción del autoempleo y la ampliación de posibilidades de captación de financiación interna. Específicamente, incluye la creación de una nueva clase de cooperativa, la cooperativa juvenil20 ${ }^{20}$ para facilitar el autoempleo cooperativo y el desarrollo profesional de la juventud gallega.

\subsection{Estrategia Gallega de Economía Social}

Aprobada por el Consello Galego Economía Social en diciembre de 2018, la Estrategia Gallega emana directamente de la LESGA, que en su disposición adicional quinta establece la necesidad de aprobar el "Plan gallego de impulso de entidades de economía social". Dicho precepto incide en la necesidad de prestar especial atención a las organizaciones de ES que generan empleo en sectores especialmente desfavorecidos, y por ello la Estrategia se dirige específicamente a más de 3.000 entidades de Galicia pertenecientes a las cuatro familias con mayor potencial para la creación de empleo: cooperativas, sociedades laborales, centros especiales de empleo y empresas de inserción.

La Estrategia, consensuada con el sector, identifica tres objetivos concretos: (1) generar más empleo y de mayor calidad, potenciando especialmente la presencia femenina entre las personas promotoras de entidades de ES; (2) garantizar una mejor redistribución de los recursos y (3) favorecer la cohesión territorial. En concreto, pretende conseguir 3.000 empleos y 300 nuevas entidades en el ámbito de la ES en el horizonte de implantación (2019-2021), para lo cual dota un presupuesto total de 73 millones de euros.

Simultáneamente, establece otros retos complementarios: sumar capacidades, sumar sostenibilidad y sumar identidad. En el primero de los retos, sumar capacidades, se agrupan aquellas medidas que pretenden fomentar la ES entre el alumnado, el impulso a los "laboratorios cooperativos en el rural"21 , la promoción del emprendimiento femenino o los incentivos a empresas de nueva creación.

20.- Ver nota 18.

21.- Los laboratorios cooperativos en el rural son iniciativas de formación, identificación de oportunidades y asesoramiento dirigidas a personas interesadas en emprender un negocio. puede ser solicitada por Concellos, mancomunidades, consorcios locales, asociaciones de entidades de economía social o asociaciones y fundaciones que tengan entre sus fines la promoción del cooperativismo y del emprendimiento. 
El segundo reto, sumar sostenibilidad, engloba aquellas medidas que contribuyen a la consolidación de empresas y la internacionalización, el impulso a la investigación y la innovación, el fomento de la responsabilidad social empresarial o la actualización de la normativa existente, haciendo una especial referencia la ley de cooperativas de Galicia.

Por último, el tercer reto, sumar identidad, está dirigido a visualizar y aumentar el sentimiento de pertenencia a la ES. Se incluye la publicación de un catálogo de entidades, la puesta en marcha del Consello Galego de ES, la dinamización de la Red Eusumo o el fortalecimiento del tejido asociativo

\subsection{Laboratorios de Apoyo a la Creación de Empleo y de Empresas de Economía Social (POCTEC LACES)}

Los Laboratorios de apoyo a la creación de empleo y de empresas de ES (LACES) es un proyecto Interreg V-A España - Portugal (POCTEP) incluido en la convocatoria 2014-2020. Este proyecto pretende contribuir al fomento de la ES en la Euroregión Galicia-Norte de Portugal para conseguir un salto cualitativo en la competitividad y el impulso de proyectos empresariales en este territorio.

Cuenta con un total de nueve socios liderados por la Secretaría Xeral de Emprego de la Xunta de Galicia. Cinco se sitúa en la comunidad autónoma, y cuatro en Portugal. En el primer grupo se incluye la propia Secretaría Xeral, la Universidad de Santiago de Compostela, la Unión de cooperativas Espazocoop, la Asociación Empresarial de Sociedades Laborais - AESGAL y la Asociación Galega de Cooperativas Agrarias. Por parte del país luso participan la Universidade Tras os Montes y Alto Douro, la Associaçã Centro de Incubação Base Tecnológica do Minho, Tecminho (unidad de innovación y emprendimiento) y la Cámara Municial de Santo Tirso.

Cuenta con un presupuesto previsto de casi 3 millones de euros, de los cuales casi 2,2 millones son financiados por fondos FEDER (Fondo Europeo de Desarrollo Regional). Entre las actividades destacan la puesta en marcha de cuatro laboratorios: (1) identificación de oportunidades de negocio, (2) creación y consolidación de empresas de ES, (3) creatividad y comunicación de la ES y (4) refuerzo y mejora de la capacitación de talento humano.

Los laboratorios se ponen en marcha entre el año 2017 y el 2019, y pretenden dar respuesta a tres grandes objetivos:

- Contribuir a visualizar y difundir la ES a través de la identificación de oportunidades de negocio vinculadas a sectores emergentes o la explotación de recursos endógenos del espacio transfronterizo.

- Perseguir la creación y consolidación de empresas de la ES favoreciendo la generación de empleo de calidad en la Eurorregión Galicia - Norte de Portugal. 
- Reforzar y mejorar la capacitación del talento humano, favoreciendo la adquisición de habilidades y competencias empresariales mediante estrategias basadas en la cooperación empresarial, las experiencias de trabajo y la formación en el sector de la ES.

\subsection{Galicia, región amiga de la Economía Social}

En el año 2019 Galicia es reconocida como Región europea amiga de la economía social (ESER 2019). Este reconocimiento emana de la Comisión Europea, concretamente de la Dirección General de Mercado Interior, Industria, Emprendimiento y PYMES en base a una convocatoria de carácter anual. La iniciativa está pensada para regiones y ciudades de la Unión Europea y tiene un doble objetivo:

1. aumentar el sentimiento de pertenencia y capacidad de la ES.

2. contribuir a la creación de redes regionales y/o locales de los actores que forman parte y están interesados en la ES.

En las regiones seleccionadas se celebrará, entre otras actividades, un evento para el que la Comisión pondrá a disposición una persona experta para participar, se facilitará una identidad visual homogénea para todas las Regiones amigas y promocionará desde los medios propios la celebración de los diferentes actos.

En el año 2019 han sido seleccionadas más de 50 regiones que forman parte de 16 países de la UE y de terceros países. En octubre todas las regiones y ciudades participarán en Bruselas en un encuentro donde se intercambiarán buenas prácticas y se delinearán áreas de colaboración futura

\subsection{Presupuestos de fomento de la economía social}

Una vez revisadas las actividades y líneas de ayuda diseñadas para el fomento de la ES, se pasa a comprobar si todo este incremento del apoyo a la ES se ve reflejado en los presupuestos autonómicos de los últimos años.

Desde el año 2016 la ES se incluye en los Presupuestos de la Comunidad Autónoma de forma específica, a través de dos líneas específicas adscritas a la Consellería de Economía, Emprego e Industria y más concretamente en la Secretaría Xeral de Emprego: (1) el programa 324C 'Promoción da economía social', donde se incorporan las medidas presupuestarias de fomento de la ES (cooperativas y sociedades laborales), y medidas de fomento y difusión de la ES (Universidades, Red Eusumo); y (2) el programa 322C 'Promoción do emprego, do emprego autónomo e do mercado de 
traballo inclusivo', que incluye las medidas para la inserción sociolaboral (Centros Especiales de Empleo (CEE) y empresas de inserción (EI)). Las líneas se reparten entre los capítulos 4 (transferencias corrientes) y 6 (inversiones reales, gastos de carácter inmaterial).

El análisis de las distintas partidas permite comprobar la distinta intensidad y prioridad de las actuaciones, así como los sucesivos cambios que se realizan en los distintos ejercicios presupuestarios (tabla 4). Las acciones del programa $322 \mathrm{C}$ se articulan a través del programa APROL-ES con el establecimiento de dos líneas de ayuda con el objetivo de fomentar la creación de empleo en cooperativas y sociedades laborales, tanto desde la propia entidad, como de la persona que accede a ese empleo. Para ello se establecen subvenciones que buscan incorporar a personas desempleadas 0 con un trabajo temporal como socias trabajadoras o de trabajo en empresas de ES. También se incluyen a personas asalariadas y socias a tiempo parcial que buscan mejorar su situación laboral dentro de la entidad. En el ejercicio 2019, sin cambiar la denominación del programa, se incorporan las medidas para la inserción sociolaboral, incorporando a las empresas de inserción laboral (EIL) y a los centros especiales de empleo (CEE). En el primer caso, se busca el fomento de la inserción laboral de personas en riesgo de exclusión social, a través del establecimiento de apoyos a las EIL con centros de trabajo en la comunidad gallega. Las subvenciones a los CEE se articulan, a su vez, a través de tres programas: i) de apoyo a los puestos de trabajo (creación, mantenimiento o ampliación); ii) de apoyo a la actividad profesional en los servicios de ajuste de personal y social de los CEE; y iii) de ayuda para el mantenimiento del coste salarial en estas entidades. Este grupo de ayudas ha sido objeto de una apuesta creciente en los últimos años, con un aumento superior al $59 \%$ en su dotación.

En 2018 se introduce un apoyo específico a los "laboratorios cooperativos en el rural", con el objetivo de dinamizar la economía local, con la identificación de oportunidades de negocio en áreas concretas. Comprende dos programas de apoyo: i) para el fomento de "laboratorios cooperativos en el rural" y ii) para el impulso de proyectos empresariales colectivos (cooperativas o sociedades laborales).

La cooperación y el asociacionismo también son objeto de ayuda, a través de un programa para sufragar los gastos de organización interna y funcionamiento de las entidades representativas de la ES (entidades asociativas de cooperativas, sociedades laborales, centros especiales de empleo y empresas de inserción). Igualmente, se destinan varias actuaciones a personas jóvenes. Para ello establece un tratamiento especial (basado en aumento de los incentivos de las cuantías) para la creación y consolidación de cooperativas juveniles. Finalmente, se establecen incentivos para la incorporación como personas socias trabajadoras o de trabajo a prueba para menores de 30 años.

Existe otro grupo de ayudas de carácter transversal. En concreto, se trata de una batería de medidas para formación, asesoramiento, acompañamiento y tutorización que buscan el buen fin de los proyectos emprendidos. La instrumentación se realizará a través de la Red Eusumo, que pone los recursos necesarios para la puesta en marcha de los proyectos, desde antes de su constitución formal hasta una vez iniciada la actividad. Este conjunto de actuaciones tiene dos vías de financiación: i) fon- 
dos finalistas, si son acciones elegibles siguiendo el Plan anual de política de empleo estatal (PAPE) y ii) fondos propios libres de Galicia.

Tabla 4. Ayudas para el fomento de la ES (2016-2019)

\begin{tabular}{|c|c|c|c|c|}
\hline & 2016 & 2017 & 2018 & 2019 \\
\hline Promoción en ES en la Universidad & & & & 20.000 \\
\hline Convenio CECOOP-USC $\left(^{*}\right)$ & 18.800 & 18.800 & 18.800 & 18.800 \\
\hline Promoción en Ec Social Cámaras de Comercio & & & 20.000 & 20.000 \\
\hline Promoción del cooperativismo y la ES & 15.000 & 20.000 & & \\
\hline Promoción ES Entidades Locales & 520.000 & 300.000 & 150.000 & 110.000 \\
\hline Impulso al cooperativismo (familias) (estudio, promoción, difusión) & 25.000 & 25.000 & 28.000 & 28.000 \\
\hline Impulso Laboratorios Cooperativos no rural & & & 500.000 & 565.000 \\
\hline $\begin{array}{l}\text { Impulso a los laboratorios cooperativos en el rural (Entidades asocia- } \\
\text { tivas) }\end{array}$ & & & & 60.000 \\
\hline Promoción del cooperativismo y la ES & 454.567 & 533.004 & 565.825 & 543.825 \\
\hline LACES & & & 76.305 & 166.970 \\
\hline Formación dual. Empresas privadas & & & & 700.000 \\
\hline Formación dual. Entidades asociativas & & & & 100.000 \\
\hline Premios a la cooperación & & & 15.000 & 15.000 \\
\hline Asociacionismo en ES & 740.000 & 754.130 & 770.000 & 790.000 \\
\hline Asociacionismo e intercooperación en ES (FSE) ${ }^{* \star}$ ) & 163.000 & 120.000 & & \\
\hline PROMOCIÓN, ESTUDIO Y DIFUSIÓN ES & 1.936 .367 & 1.770 .934 & 2.143 .930 & 3.137 .595 \\
\hline Fomento Emprendimiento Ec Social $\left.(\mathrm{FSE}+\mathrm{CA}){ }^{(* \star}\right)$ & 2.391 .346 & 2.611 .292 & 1.050 .000 & 1.068 .155 \\
\hline Fomento Acceso condición socios ES (FSE) & & & 800.000 & 1.000 .000 \\
\hline Medidas de apoyo a empresas de ES & & & & 500.000 \\
\hline Garantía Juvenil en ES & 652.955 & & & \\
\hline Fomento del cooperativismo en garantía juvenil & 217.652 & 870.607 & & \\
\hline COOPERATIVAS Y SOCIEDADES LABORALES & 3.261 .953 & 3.481 .899 & 1.850 .000 & 2.568 .155 \\
\hline Medidas de Apoyo a CEE entidades privadas ${ }^{* * * *}$ ) & & 1.450 .000 & 2.012 .500 & 1.850 .000 \\
\hline $\begin{array}{l}\text { Coste salarial de personas con discapacidad en CEE. Empresas } \\
\text { privadas }\end{array}$ & 7.849 .615 & 8.080 .522 & 9.328 .647 & 9.950 .000 \\
\hline $\begin{array}{l}\text { Ayudas a la contratación de personas con discapacidad y empleo con } \\
\text { apoyo }\end{array}$ & & 1.080 .000 & 1.182 .789 & \\
\hline
\end{tabular}




\begin{tabular}{|c|c|c|c|c|}
\hline Medidas de apoyo a CEE. Entidades asociativas. & & 170.000 & 297.500 & 140.000 \\
\hline Coste salarial de personas en CEE. Entidades asociativas. & 950.000 & 720.000 & 896.821 & 860.000 \\
\hline Incentivos a empresas promotoras de ElL $\left(^{* * * *}\right)$ & 24.715 & 10.000 & 10.000 & 10.000 \\
\hline Incentivos a ElL & 200.000 & 200.000 & 368.790 & 370.000 \\
\hline Contratación de personas con discapacidad y personal de apoyo. & & 220.000 & 220.000 & \\
\hline Integración laboral de colectivos vulnerables & & & & 1.200 .000 \\
\hline CEE y EIL & 9.024 .330 & 11.930 .522 & 14.317 .047 & 14.380 .000 \\
\hline TOTAL & 14.222 .650 & 17.183.355 & 18.310 .977 & 20.085 .750 \\
\hline
\end{tabular}

FUENTE: Elaboración propia con datos de los Presupuestos Generales de la Comunidad Autónoma de Galicia.

El gráfico 4 permite ampliar el foco de análisis, reflejando la evolución del presupuesto destinado al fomento de la ES desde 2008. Como se puede comprobar, en este período se ha producido un incremento de los fondos próximo al $16 \%$, pasando de destinar 17 a más de 20 millones de euros. Sin embargo, la evolución no ha sido constante en el periodo analizado. En primer lugar, entre 2008 y 2010 -coincidiendo con el inicio de la crisis económica- se distingue una primera etapa de decrecimiento, con una caída próxima al $12 \%$ de la dotación presupuestaria. Esta situación se revierte en el bienio 2011-2012, donde se registra un incremento muy notable vinculado con el aumento de los fondos destinados a las unidades de apoyo de los CEE y EIL. Por su parte, el resto de las partidas reflejan una evolución mucho más suave, con un incremento moderado. A partir de 2013, año en que empieza a funcionar la Red Eusumo, se inicia una senda expansiva suave y sostenida que se mantiene hasta la actualidad. En este período cabe destacar el año 2019, con el mayor presupuesto de la serie observada y un incremento de algo más de 3 millones de euros respecto del año anterior (un 10 $\%$ ), que podría estar vinculado con la implantación de la estrategia gallega de ES. La dotación prevista este año prácticamente iguala la de 2012, año con el mayor presupuesto de fomento. 


\section{Gráfico 4. Evolución del presupuesto para el fomento de la economía social, 2008-2019, en millones de euros}

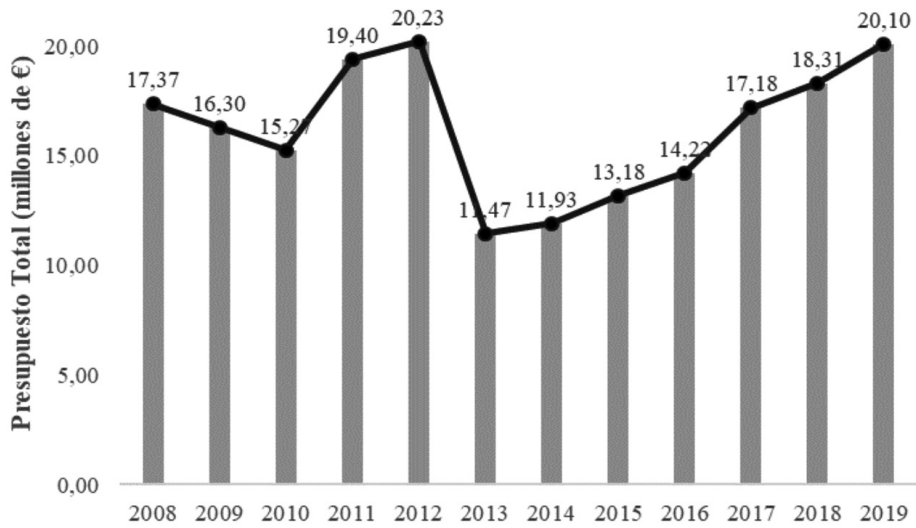

FUENTE: Elaboración propia con base en los presupuestos de la Xunta de Galicia.

El análisis global del período (gráfico 5) constata que la apuesta por la ES en Galicia se ha visto refrendada por una dotación incremental en los presupuestos de la comunidad autónoma, con un aumento de las partidas destinadas a este fin que registra un crecimiento promedio del $1,34 \%$ anual. Si se desagrega el período en los años anteriores y posteriores a la creación de la Red Eusumo, se observa que el ritmo de crecimiento en esta dotación presupuestaria más que se duplica, pasando de un 3,88 \% de aumento entre 2008 y 2012 a un 9,81\% de media anual entre 2013 y 2019 . Igualmente, la aprobación de la LESGA en 2016 resulta determinante en la configuración de los presupuestos: entre este año y 2019 las partidas destinadas a la ES han crecido a un promedio del 12,21 \% anual.

\section{Gráfico 5. Evolución del presupuesto para el fomento de la economía social, 2008-2019. TCA}

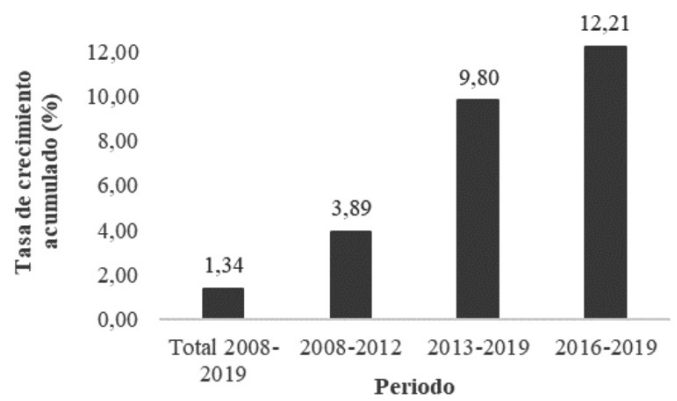

FUENTE: Elaboración propia con base en los presupuestos de la Xunta de Galicia 
Un análisis más pormenorizado, centrado en la evolución de cada grupo de medidas, (gráfico 6), revela que son las medidas de fomento a los CEE y El son las que reciben más fondos: en el año 2019, representan un $72 \%$ del total del presupuesto de fomento a la ES. Sin embargo, las medidas dirigidas al fomento, estudio y difusión de la ES y las de fomento de cooperativas y sociedades laborales representan un $15 \%$ y un $13 \%$ respectivamente en este año. En cuanto a la evolución, estas mismas partidas son las que registran un mayor crecimiento, un $60 \%$ desde el inicio al final del periodo analizado. Las partidas destinadas a la promoción, fomento y difusión también se han visto incrementadas, pero en menor medida, un $23 \%$. Sin embargo, las dirigidas al fomento de cooperativas y sociedades laborales han sufrido una disminución del $30 \%$.

\section{Gráfico 6. Evolución del presupuesto para el fomento de la economía social por tipos de medidas, 2008-2019 (en millones de euros)}

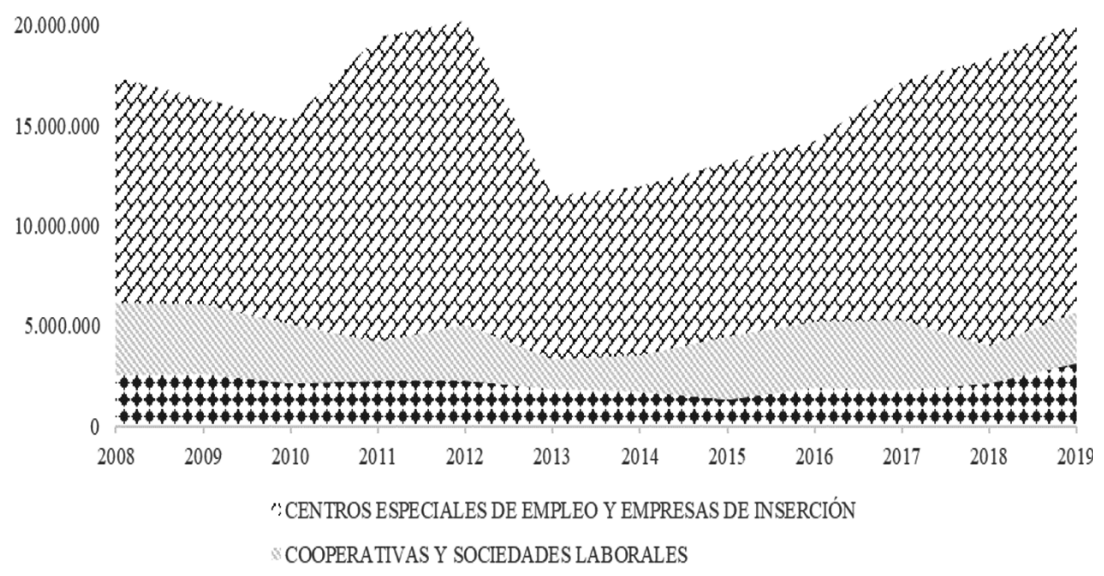

• PROMOCIÓN, ESTUDIO Y DIFUSIÓN ECONOMÍA SOCIAL

FUENTE: Elaboración propia con base en los presupuestos de la Xunta de Galicia. 


\section{Conclusiones}

Este trabajo se planteó con el objetivo de describir la Red Eusumo y valorar su eficacia desde su constitución en 2012. En este sentido, se pueden determinar dos tipos de resultados: (a) resultados directos, vinculados con los objetivos de fomento y promoción de la economía social y el cooperativismo, así como del empleo y emprendimiento; y (b) resultados indirectos, con incidencia sobre la mejora del ecosistema de la economía social en Galicia.

En relación con los primeros, la Red ha contribuido al conocimiento y difusión de la ES en Galicia, con numerosas acciones formativas y divulgativas que atraen a un número creciente de personas interesadas. En estos años la Red Eusumo se ha consolidado, duplicando su número de socios y extendiendo su influencia a más del $60 \%$ de los ayuntamientos gallegos. Las acciones desarrolladas por la Red han contribuido a la consolidación de las entidades existentes, que han encontrado en la Red un instrumento de ayuda y asesoramiento. Sin embargo, su repercusión en el desarrollo del número de entidades es limitada, máxime teniendo en cuenta que el incremento en la creación de organizaciones puede estar relacionado con múltiples factores.

La valoración de los resultados indirectos es más positiva. Desde el nacimiento de la Red, Galicia ha aprobado su propia Ley de Economía Social, una Estrategia de Economía Social, y diversos órganos de coordinación para la gestión de entidades y asociaciones, que giran alrededor del impulso presupuestario de Eusumo. Todas estas iniciativas, además, se han visto reflejadas en sucesivas dotaciones incrementales en los presupuestos generales de la Comunidad Autónoma, con un aumento progresivo de la dotación al fomento y desarrollo de la ES próximo al $10 \%$ desde el nacimiento de la Red. Por tanto, la Red Eusumo actúa como motor presupuestario centralizado para el desarrollo e impulso de un ecosistema favorable a la ES en Galicia.

Estos resultados sitúan a la Red Eusumo como una combinación entre las políticas de fomento blandas y duras, en la clasificación ampliamente reconocida en el ámbito académico del apoyo de las políticas públicas de fomento a la ES (Chaves 2002; Chaves y Monzón, 2018; ver Chaves y Savall (2019) para una reciente revisión en esta temática). Las primeras (políticas blandas) tienen como objetivo establecer un ecosistema favorable para el desarrollo de empresas de ES, pudiendo dividirse en políticas institucionales (dirigidas al establecimiento de una estructura legal de estas entidades, su plena incorporación a la actividad económica, su papel como interlocutor en tanto que agente social, y estableciendo una estructura específica para la centralización de estas actividades) y políticas cognitivas, cuyo objetivo es aumentar el conocimiento, aprendizaje y estudio de la ES. Por su parte, las políticas duras son intervenciones directamente orientadas al desarrollo de la actividad económica 
de las entidades de ES (sea incidiendo en la oferta o la demanda). La Red Eusumo, dirigida desde una división específica de la administración autonómica, ha impulsado el desarrollo de la LESGA y sentado las bases del Consello Galego de ES (políticas blandas institucionales), y en su valoración ha contribuido principalmente al conocimiento y difusión de la ES en Galicia (blandas cognitivas). Pero, además, las medidas de asesoramiento, acompañamiento y las dirigidas al establecimiento y consolidación de las entidades de ES, la sitúan en el marco de desarrollo de las consideradas políticas duras de fomento.

La evaluación de resultados de la Red apunta a una mejor valoración de las políticas blandas, tanto en su dimensión institucional como cognitiva. A la espera de resultados de las iniciativas más recientes (vinculadas concretamente con la LESGA o la Estrategia Gallega de ES), sí puede detectarse una serie de deficiencias que pudieran restar cierta eficacia, y cuya reversión podría generar las sinergias esperadas de este ecosistema. Como se ha reflejado en este análisis, Eusumo es una herramienta viva, que se renueva en cada convocatoria ajustándose a las condiciones del entorno y poniendo el foco en la priorización de diferentes actividades y entidades. En concreto, se plantean diferentes medidas dirigidas a la mejora de todo el proceso de administración de la Red:

- En lo que respecta a su planificación y estructura de organización, la alineación horizontal y vertical de los programas y acciones podría mejorar la implantación de la estrategia. Horizontalmente, sería aconsejable establecer una red de entidades tractoras con mayor proximidad y acceso al tejido de ES, ayudando a facilitar, de esta forma, la capilaridad del alcance de las ayudas y las acciones concretas. Esta red, a su vez, permitiría mejorar la coordinación de las actividades, para un mejor encaje en las líneas estratégicas (alineación vertical).

- A pesar del aumento del número de socios, el compromiso asumido por cada uno de ellos es limitado e irregular. En este sentido, una cierta descentralización podría actuar como palanca de su implicación. De forma similar, si bien se ha destacado el liderazgo de la Administración Autonómica como prueba de su compromiso con la ES, sería deseable que las prioridades y programas se determinasen de forma participativa, respondiendo mejor a los principios subyacentes a la ES y revertiendo, igualmente, en la mejora de la implicación. Igualmente, la gestión de la Red Eusumo debería estar reservada a una entidad de la ES, en concordancia con los principios subyacentes a su propia definición.

- En los resultados, se observa que las cooperativas son las entidades en las que más impacto ha tenido la Red Eusumo, por lo que respecta al número de entidades creadas. Parece, también, que la Red sigue focalizando sus intereses en dichas organizaciones. En consecuencia, debería impulsarse el conocimiento, difusión y alcance de acciones y recursos para el resto de las familias de la ES, y en particular para aquellas que la propia Estrategia Gallega de ES identifica como potenciales generadoras de empleo (sociedades laborales, centros especiales de empleo y empresas de inserción). Esto supondría pasar de la consideración de una herramienta de fomento del cooperativismo a otra de impulso a un sistema de ES. 
- Se detecta cierto recorrido de mejora en el establecimiento de políticas duras de fomento a la ES. En concreto, aquellas que pudiesen incidir en la demanda de productos y servicios de entidades de ES. En este sentido, y pese a que las normativas más recientes obligan a la compra pública responsable tanto con la introducción de cláusulas sociales como con el establecimiento de contratos reservados ${ }^{22}$, ambas figuras cuentan con una escasa incidencia en la actualidad.

- En lo que respecta a las políticas blandas, también está pendiente la incorporación formal de los estudios centrados en la ES. Ninguna de las tres universidades gallegas incluye estudios en este ámbito, siendo básicos para impulsar su desarrollo y consolidación como una vía de desarrollo profesional.

- Finalmente, sin menosprecio del efecto que las microcooperativas puedan tener en el autoempleo y -en el caso de las cooperativas juveniles-en su contribución a la incorporación de personas jóvenes a la actividad profesional, el aumento del tamaño de las entidades es básico para mejorar su competitividad y sus posibilidades de crecimiento, por lo que resulta imperativo establecer medidas de apoyo en este sentido (fusiones o alianzas estratégicas, por ejemplo).

La incorporación de alguna de estas medidas puede mejorar el resultado de la Red, convirtiéndola en un elemento diferencial para la mejora de la competitividad de las organizaciones de ES y convirtiendo a ésta en un motor básico del funcionamiento de la economía gallega. Por sus características, además, estas entidades pueden ser críticas en la reversión de los fenómenos de dispersión, hiperconcentración poblacional y abandono de tierras característico de la demografía gallega.

\section{Bibliografía}

AMIN, A. (2013): The social economy: International perspectives on economic solidarity, Zed Books Ltd.

BASTIDA DOMínGUEZ, M., OLVEIRA BLANCO, A. y CANCELO MÁRQUEZ, M. (2018): Políticas públicas para a Economía Social en Galicia: Rede Eusumo, Centro de Estudios Cooperativos CECOOP.

CALDERÓN, B. y CALDERÓN, M.J. (2012): "La calidad del empleo de las entidades de la economía social en período de crisis", EKONOMIAZ, Revista vasca de Economía, 79 (1), 31-58.

22.- Ambas figurar introducidas en la Ley 9/2017, de 8 de noviembre, de Contratos del Sector Público. 
CHAVES, R. (2002): "Politiques Publiques et Economie Sociale en Europe. Le Cas de l'Espagne", Annals of Public and Cooperative Economics, 73(3), 453-480, https://doi.org/10.1111/14678292.00200 .

CHAVES, R. \& DEMOUSTIER, D. (2013): The emergence of the social economy in public policy, Brussels: Peter Lang.

CHAVES ÁVILA, R. y SAVALL MORERA, T. (2013): "La insuficiencia de las actuales políticas de fomento de cooperativas y sociedades laborales frente a la crisis en España", REVESCO. Revista de Estudios Cooperativos, 113, 61-91, https://doi.org/10.5209/rev-REVE.2014.v113.43383.

CHAVES ÁVILA, R. \& SAVALL MORERA, T. (2019): "The Social Economy in a Context of Austerity Policies: The Tension Between Political Discourse and Implemented Policies in Spain", VOLUNTAS: International Journal of Voluntary and Nonprofit Organizations, 30(3), 487-498. https://doi. org/10.1007/s11266-018-00075-3

CHAVES ÁVILA, R., SAVALL MORERA, T. y MONZÓN CAMPOS, J.L. (2016): "La política presupuestaria de fomento de la Economía Social en España en un contexto de austeridad". En: Presupuesto y Gasto Público, pp. 89-106. Retrieved from http://hdl.handle.net/10550/58669.

CHAVES, R. \& MONZÓN, J.L. (2018): "The social economy facing emerging economic concepts: Social innovation, social responsibility, collaborative economy, social enterprises and solidary economy", CIRIEC-España, Revista de Economía Pública, Social y Cooperativa, 93, 5-50. https://doi. org/10.7203/ciriec-e.93.12901.

DÍAZ, M. y MARCUELLO, C. (2010): "Impacto económico de las cooperativas. La generación de empleo en las sociedades cooperativas y su relación con el PIB", CIRIEC-España, Revista de Economía Pública, Social y Cooperativa, 67, 23-44.

DÍAZ, M. y MARCUELLO, C. (2014): "The Relation between Total Employment and Cooperative Employment: A Convergence and Causality Analysis", Spatial Economic Analysis, 9 (1), 71-92 https:/l doi.org/10.1080/17421772.2013.864048.

EUROPEAN UNION COUNCIL CONCLUSIONS (December 2015): Luxembourg Presidency. The promotion of the $S E$ as a key driver of economic and social development in Europe, Brussels (15071/15 SOC 711 EMPL 464).

FERNÁNDEZ GUADAÑO, J., MARTíN LÓPEZ, S. y LEJARRIAGA PÉREZ DE LAS VACAS, G. (2010): "Retos del trabajo autónomo para afrontar la crisis económico-financiera", Economistas, 28(124), 99-113.

GARCÍA-GUTIÉRREZ, C. (2002): "La empresa de participación: características que la definen. Virtualidad y perspectivas en la sociedad de la información", CIRIEC-España, Revista de economía pública, social y cooperativa, 40, 99-122. 
HERRERO BLASCO, A. (2012): La fiscalidad como política de fomento de la economía social. El caso de la fiscalidad de las cooperativas en España, Universidad de Valencia.

JAÉN GARCÍA, M. (2017): "Crisis económica y economía social", REVESCO, Revista de Estudios Cooperativos, 126, 74-93. https://doi.org/10.5209/REVE.58394.1.

LEJARRIAGA PÉREZ DE LAS VACAS, G., BEL DURÁN, P. y MARTíN LÓPEZ, S. (2013): "El emprendimiento colectivo como salida laboral de los jóvenes: análisis del caso de las empresas de trabajo asociado", REVESCO, Revista de Estudios Cooperativos, 112, 36, https://doi.org/10.5209/ rev_REVE.2013.v112.43068.

MARTíN LÓPEZ, S., GARCÍA-GUTIÉRREZ FERNÁNDEZ, C. y LEJARRIAGA PÉREZ DE LAS VACAS, G. (2010): "Las dificultades de financiación de las empresas de participación ante la crisis económica: la creación de una entidad financiera de crédito como alternativa", REVESCO, Revista de Estudios Cooperativos, 100, 11-42.

MARTÍNEZ-CARRASCO PLEITE, F., LÓPEZ YEPES, J.A. y MARÍN RIVES, J.L. (2013): "Estrategias, estilos de dirección, compromiso de los trabajadores, responsabilidad social y desempeño de las pequeñas y medianas empresas de economía social de la región de Murcia", REVESCO, Revista de Estudios Cooperativos, 111, 108-136, http://dx.doi.org/10.5209/rev_REVE.2013.v111.426754.

MELGAREJO, Z., ARCELUS, F.J. y SIMÓN, K. (2007): "Una evaluación crítica del potencial de supervivencia de las sociedades laborales", CIRIEC-España, Revista de Economía Pública, Social y Cooperativa, 59, 181-202.

MELIÁN NAVARRO, A. y CAMPOS CLIMENT, V. (2010): "Emprendedurismo y economía social como mecanismos de inserción sociolaboral en tiempos de crisis", REVESCO, Revista de estudios cooperativos, 100, 43-67.

MONZÓN, J.L. (1991): "Análisis del empleo en la economía social", Revista de economía y sociología del trabajo, 12, 17-24.

MONZÓN, J.L. \& CHAVES, R. (2012): The social economy in the European Union, European Economic and Social Comittee \& CIRIEC, https://doi.org/10.2864/19534.

MONZÓN CAMPOS, J.L. (2010): La Economía Social en España en el año 2008, CIRIEC-España, Ed., Valencia.

MONZÓN, J.L., ORTEGA CALVO, R., CHAVES ÁVILA, R., FAJARDO GARCÍA, I.G., y VALDÉS DALRÉ, F. (2009): Informe para la elaboración de una Ley de Fomento de Economía Social.

SALA, M., TORRES, T. y FARRÉ, M. (2015): "El empleo de las cooperativas. Un análisis comparativo de sus fases cíclicas y de su grado de sincronización", CIRIEC-España, Revista de Economía Pública, Social y Cooperativa, 83, 115-141. 
SALA, M., TORRES, T. y FARRÉ, M. (2018): "Demografía de las cooperativas en tiempos de crisis", CIRIEC-España, Revista de Economía Pública, Social y Cooperativa, 93, 51-84. DOI: https://doi. org/10.7203/CIRIEC-E.93.11042.

SALINAS, F. y OSORIO, L. (2012): "Emprendimiento y Economía Social, oportunidades y efectos en una sociedad en transformación", CIRIEC-España, Revista de Economía Pública, Social y Cooperativa, 75, 129-143.

STIGLITZ, J.E. (2009): "Moving beyond market fundamentalism to a more balanced economy", Annals of Public and Cooperative Economics, 80:3, 345-360.

OLVEIRA, A. (2016): "Emprendimiento Cooperativo en Galicia con perspectiva de género: una forma de afrontar la crisis económica (2008-2014)", 6a Conferencia lbérica de Emprendimiento, 38-41.

UTTING, P. (Ed.)(2015): Social and solidarity economy, London: UN-RISD and Zed Books.

WILKINSON, C., MEDHURST, J., HENRY, N., WIHLBORG, M. \& BRAITHWAITE, B.W. (2014): A map of social enterprises and their eco-systems in Europe: Excutive Summary. A report submitted by ICF Consulting Services, European Commission. 